\title{
The importance of thermography for injury prevention and performance improvement in olympic swimmers: a series of case study
}

\begin{abstract}
Sports medicine operates in two main areas: injury prevention and the performance improvement. Medical infrared thermography has been devoted to understand sports performance and pathology diagnostic, showing a potential to ensure better results for athletes due to the ability to identify risks, prevent injuries and increase performance. The aim of this study is to present the results of thermographic evaluation, in a series of case study, and it is role in preventing injury and improving the performance of high performance athletes from the Brazilian Olympic Swimming Team. The results obtained demonstrated the importance of the use of thermography, the possibilities of intervention and, also, the consequent improvement in clinical and training aspects.
\end{abstract}

Volume 3 Issue 2 - 2018

\author{
Ana Carolina Ramos e Côrte', Guilherme \\ Henrique Ramos Lopes ${ }^{2}$, Manoel Moraes ${ }^{3}$, \\ Rafael Martins de Oliveira ${ }^{4}$, Marcos Leal \\ Brioschi ${ }^{5}$,Arnaldo José Hernandez ${ }^{6}$
}

'Sports Medical Speciality of Hospital das Clínicas da Faculdade de Medicina da Universiade de São Paulo, Brazil

${ }^{2} \mathrm{MsC}$, Substitute Professor of Faculdade de Educação Fisica da Universidade de Brasília, Brazil

${ }^{3}$ Biomechanical of Confederação Brasileira de Desporto Aquático (CBDA), Brazil

${ }^{4}$ Manual Therapy of Confederação Brasileira de Desporto Aquático (CBDA), Brazil

${ }^{5}$ Medical Thermography Specialty of Sao Paulo University Hospital, Brazil

${ }^{6}$ Orthopediac Speciality of Hospital das Clínicas da Faculdade de Medicina da Universidade de São Paulo, Brazil

Correspondence: Ana Carolina Ramos e Côrte, Sports Physician, Faculty of Medicine, Institute of

Orthopedics and Traumatology, Group of Sports Medicine, University of São Paulo, Brazil, Email anacarolinacorte@usp.br

Received: October 24, 2017 | Published: March 20, 2018

\section{Introduction}

Nowadays, Sports Medicine needs safe methods that can work on these two pillars. Injury prevention is linked to imbalance of strength, range of motion, stretching and posture. ${ }^{1,2}$ In addition, clinical aspects such as nutrition and sleep quality are also important. Likewise, the increase of performance is linked to the same clinical features and the ability to play the sport gesture with the best efficiency.

Swimming is a sport that the main injuries, such as tendinopathy of the rotator cuff and mechanical low back pain, are the result of local overload by repetition of moves. ${ }^{3,4}$ Diagnosis of these injuries have done by using ultrasound or magnetic resonance imaging (MRI) and spent a lot of time to be carried out. Moreover, ultrasound is examiner dependent and MRI emits radiation and cannot be done in field of play.

Medical Infrared Thermography (MIT) is a non-radiating and contact-free technology to monitor physiological functions related to skin temperature control..$^{5}$ The efficiency, safety and low cost of MIT make it an useful auxiliary tool for detecting and locating thermal abnormalities characterized by increases or decreases in skin surface temperature. It is also capable of identifying the cutaneous vasomotor changes related to injury, inflammation, wound healing and microcirculation. ${ }^{6}$ this method provides real-time, instantaneous visual images with measurements of surface temperatures and is able to show physiological changes. ${ }^{7-11}$
It is well known that sports activity induces a complex thermoregulation process where part of heat is given off by the skin of athletes. As not all the heat produced can be entirely given off, there follows a muscular heating resulting in an increase in the cutaneous temperature. ${ }^{12-15,9}$ A difference higher than 1 degree centigrade between body-sides should indicate a pathophysiological process. ${ }^{16}$

In Sports Medicine, some studies using MIT have been devoted to understand sports performance and pathology diagnostic, showing a potential to ensure better results for athletes due to the ability to identify risks, prevent injuries and increase performance. ${ }^{13,17}$ A recent review demonstrated the efficacy of MIT's for prevention, rehabilitation and training load control in recreational and competitive athletes. ${ }^{18}$

In swimming, as in other high performance sports, good results are related to the sporting technique, static posture, and muscle strength balance, range of motion and neuromotor control. ${ }^{19}$ The infrared thermography image has the potential to show static and dynamic posture, range of motion balance, and identify overhead areas during exercise. ${ }^{20}$ Lavoie e Montpetit (1986) studied a group of swimmers with termography and the termograms indicated a significant increase in the cutaneous temperature in accordance with the swimming style. ${ }^{21}$ It appears that the highest temperature is reached in the upper part of the body for the backstroke style. From an energy point of view, backstroke seems to be the most demanding style. However, there are still a few studies verifying the use of thermography in swimming athletes for planning interventions on injury prevention and performance improvement. 
Nowadays, there are some useful, but not specific tests for measuring maximal exercise ability in swimmers. Most of them use the lactate level (invasive test) to quantify the exercise intensity. Heart rate and ratings of perceived exertion are also used. ${ }^{22}$ However, no one can identify regions of interest of human body with no contact or radiation and easy to reproduce in a short time and completely innocuous. MIT is a potential tool to identify early local cutaneous vasomotor changes in the objective assessment of the athlete's heat production, in order to prevent injuries and to quantify the workload.

\section{Objective}

The aim of this study is to present the results of MTI evaluation and it is role in preventing injury and improving the performance of high performance athletes from the Brazilian Olympic Swimming Team, during Altitude Training Camping in Flagstaff, Arizona, in 2016.

\section{Materials and methods}

A series of case study, aimed to illustrate the potential clinical application of thermography in sports.

\section{Participants}

Five male athletes of the Brazilian Olympic Swimming Team were selected for altitude training camping in Flagstaff, Arizona. These swimmers were chosen because they had been qualified during Brazilian's trials for the Rio de Janeiro Olympic Games.

\section{Medical evaluation}

Physical examination was performed in each athlete at the start and during the training camping and executed by Brazilian medical physician and physiotherapist. Visual Analogic Scale (VAS) was used and asked if there is a pain during the physical examination. Perceived exertion (Borg Scale) was used and asked if there is fatigue complain after training.

\section{Thermography data collection and analysis}

Thermographic measurements from the front and back surfaces of each participant were acquired in a standing upright resting position. Environmental conditions during the tests were $23^{\circ} \mathrm{C} \pm 0.5^{\circ} \mathrm{C}$ and 49 $50 \%$ of relative humidity air during all trials.

All thermographic images were recorded digitally by a thermography camera with an infrared resolution of 160 X 120 pixels and thermal sensitivity of $0.1^{\circ} \mathrm{C}$ (FLIR ONE, USA). The camera was positioned 2-4 $\mathrm{m}$ far away from the subjects and kept perpendicular to regions of interest. Images were recorded in a controlled environment (with light and temperature controlled room), and were stored for offline analysis using a commercial software (FLIR Tools, USA). All images were processed using an emissivity factor of 0.98 to obtain human skin temperatures.Participants were allowed to acclimatize to their ambient temperature for a period of 20 minutes, in concordance with standard recommendations followed in the literature. $8,23,24$

In color scale was used, and the highest temperature was represented by white, red as an intermediate temperature, yellow as a cold temperature, blue as colder than yellow and black color, the coldest temperature.

\section{Intervention}

The MTI analysis was performed during the first week of an altitude training camp in which the athletes maintained a routine of workouts
$20 \%$ less than the training that they had been performing previously. The training routine consisted of a double shift of swimming workouts daily $( \pm 6000 \mathrm{~m}$ per day) and strength training three times a week. Although the main event of some athletes weren't crawl, during the most part of the training, the athlete swims crawl style.

Before the analysis, a physical therapy intervention (PT) was prescribed for each athlete based on passive stretching, strength, myofascial release, joint mobilization and postural correction.

\section{Results and discussion}

A total of 5 (five) male athletes with a mean age of 22 years (18.926.1 year old), were included in the study. No one individual was excluded during research. Mean weight for the study sample was $82.3 \mathrm{~kg}$ (72.2- 96.4; SD 14) and mean height was 1.82m (1.73-1.94; SD?). At medical anamnesis, all participants didn't complain about any symptoms.

Only one of the swimmers had a symmetric thermogram and did not relate any symptoms, even during physical examination. This study has shown that $80 \%$ of the group had an asymmetric thermogram and infrared thermography can be a great tool for medical practice in the evaluation of swimmers.

The results will be presented for each athlete, who had an asymmetric thermogram, due to specificities of the collected data and interventions performed.

\section{Case I: A 25-year-old Brazilian swimmer, whose main event is $200 \mathrm{~m}$ breaststroke}

Thermographic image (Figure 1) shows higher temperature on the left side before the intervention, related with an overuse caused by the use of his left side for breathing during crawl style, associated to a muscle imbalance. Temperature conjugated gradients $(\Delta \mathrm{T})$ between left and right abdominal region was $0.5^{\circ} \mathrm{C}$ (Table 1). Maximum temperature of $28.1^{\circ} \mathrm{C}$ in left side and $27.7^{\circ} \mathrm{C}$, in right side. Minimum temperature of $26.7^{\circ} \mathrm{C}$ in left side and $26.3^{\circ} \mathrm{C}$, in right side. At the moment of the image acquisition, the athlete did not complain of pain.

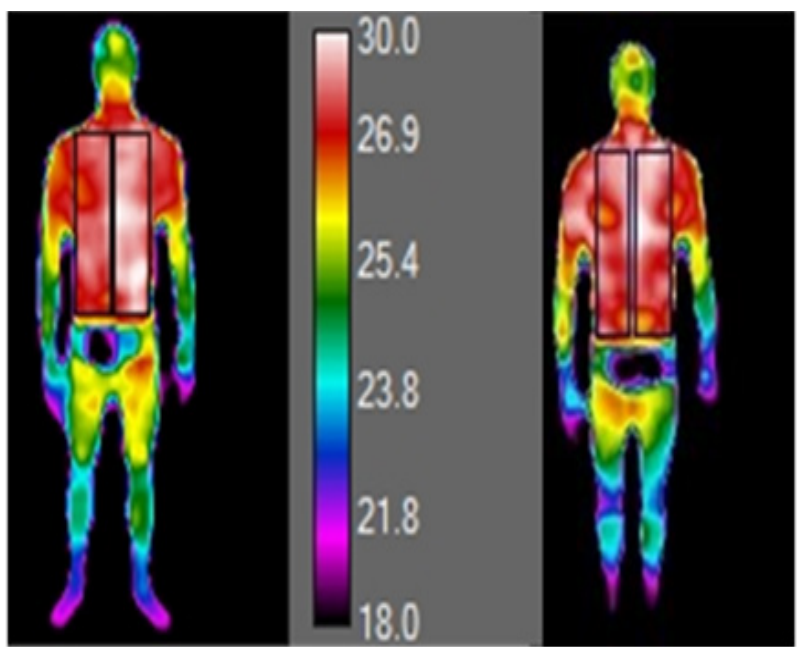

Figure I MIT images before and after PT intervention (two region of interest were marked: trunk/chest).

After the analysis of the MIT, a physiotherapy intervention was started with the aim of correcting thermal imbalance (stretching, articular mobilization and manual therapy). One day after session, $\Delta \mathrm{T}$ 
between left and right abdominal region was $0.2^{\circ} \mathrm{C}$ and the hyperradiation on the left side was no more seen (Table 1) (Figure 1).

During specific training of breaststroke, some underwater images were realized before intervention, and were observed that legs were apart and misaligned, since the beginning until the end of the movement because of a hip misaligned. In addition, left leg also was deeper than right leg. The hip misaligned reflects on arms movement during slipping (Figure 2). This imbalance is usually consequence of muscle fatigue of left body side, and it can explain the thermography asymmetries found in this case.

Table I Termography values $\left({ }^{\circ} \mathrm{C}\right)$ on right side and left side of the body and temperature conjugated gradient $(\Delta \mathrm{T})$ of each athlete before and after physical therapy intervention

\begin{tabular}{lllllll}
\hline Athlete & Before & \multicolumn{5}{c}{ After } \\
\cline { 2 - 7 } & Right Mean $( \pm \mathbf{S D})$ & Left Mean $( \pm \mathbf{S D})$ & $\Delta \mathbf{T}$ & Right Mean $( \pm \mathbf{S D})$ & Left Mean $( \pm \mathbf{S D})$ & $\Delta \mathbf{T}$ \\
\hline Case I & $27.1( \pm 0.3)$ & $27.6( \pm 0.2)$ & 0.5 & $24.5( \pm 0.3)$ & $24.6( \pm 0.4)$ & 0.1 \\
Case 2 & $26.7( \pm 0.2)$ & $26.3( \pm 0.5)$ & 0.4 & $23.4( \pm 0.3)$ & $23.2( \pm 0.3)$ & 0.2 \\
Case 3 & $22.2( \pm 0.2)$ & $23.0( \pm 0.3)$ & 0.8 & $19.9( \pm 0.2)$ & $20.2( \pm 0.3)$ & 0.3 \\
Case 4 & $23.4( \pm 0.3)$ & $23.2( \pm 0.3)$ & 0.2 & $22.0( \pm 0.2)$ & $22.4( \pm 0.2)$ & 0.4 \\
\hline
\end{tabular}

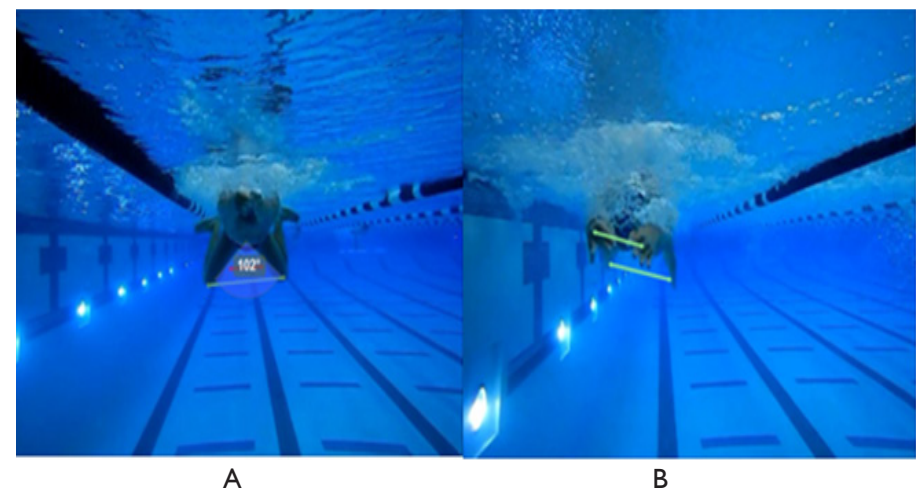

Figure 2 Underwater images during breaststroke training. A) knee misaligned B) left leg deeper than right.

\section{Case 2: A 19-year-old Brazilian swimmer, whose main events are $400 \mathrm{~m}$ freestyle and $200 \mathrm{~m}$ butterfly}

Thermographic image (Figure 3) shows a hyper-radiant area in anterior scapular waist with focus on right side: difference of temperature among two sides was $0.4^{\circ} \mathrm{C}$ (Table 1). During physical examination, athlete complained of posterior left shoulder pain compatible with retraction of posterior capsule.

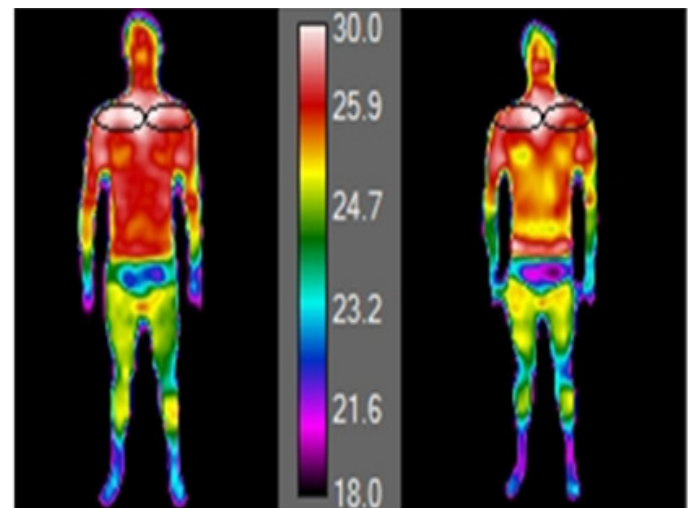

Figure 3 MIT images before and after PT intervention (region of interest were marked: anterior scapular.

After three days of physiotherapy treatment based on passive stretching, myofascial release and join mobilization, the temperature delta decreased to $0.2^{\circ} \mathrm{C}$, which is considered normal limit (Figure 3) (Table 1). Daily exercises to gain left internal rotation were also performed, to get bilateral balance of range of motion. The internal rotation deficit observed was responsible for overload showed in thermography of right shoulder girdle, due to a muscle strength imbalance generated during swimming.

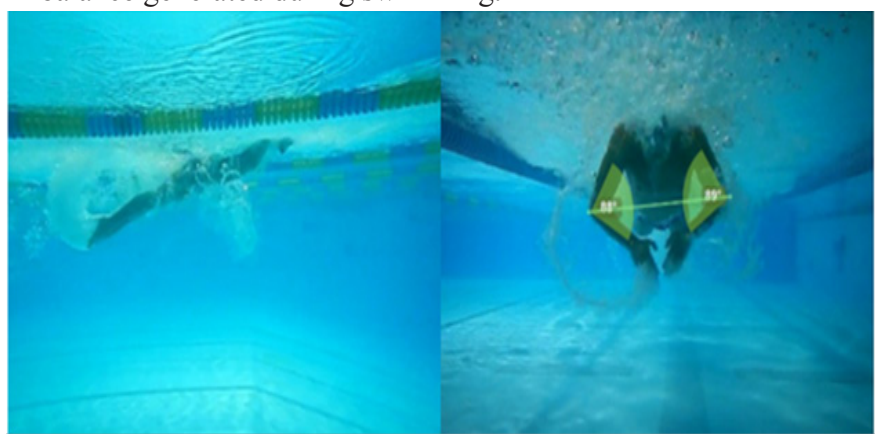

A

$B$

Figure 4 Biomechanics analysis. A) verticalization B) difference between internal rotation.

Biomechanical analysis of swimming showed an inefficient sporting gesture by verticalization. During the time of breathing, the trunk and lower athlete members tend to verticalize with a decrease of the elbow and, then, the hands were positioned downward. For a good support of the arms in the water, a shoulder joint mobility is required. The shoulder internal rotation is essential to ensure greater support of grip

Due to the downturn and the limitation on the left shoulder internal rotation (Figure 4) the athlete stroke movement was impaired by overloading the asymptomatic side. Glenohumeral internal rotation deficit (GIRD) was 46.9 degrees. Thus justifying the overload of anterior shoulder girdle of right shoulder.

\section{Case 3: A 26-year-old Brazilian swimmer, whose main event is $200 \mathrm{~m}$ freestyle}

Figure 5 portrays a symptomatic athlete in clinical evaluation. Temperature conjugated gradients between medial region of left and right thigh was $0.8^{\circ} \mathrm{C}$ (Table 1). The maximum temperature of medial region of left thigh was $23.6^{\circ} \mathrm{C}$ and in the contralateral region, $22.8^{\circ} \mathrm{C}$.

During clinical evaluation, the athlete complained of pain during palpation at the proximal insertion of left adductor, eight points at VAS. The hyper-radiation left image associated with clinical examination showed an acute tendinopathy of left adductor. With the clinical diagnosis established, the athlete underwent physiotherapy to 
treat the injury and returned thermal symmetry after three treatment days $\left(\Delta \mathrm{T}=0.3^{\circ} \mathrm{C}\right)$. After that, there was no pain during clinical examination; however, a minimal terminal difference was still present. The athlete was then oriented to do every day some cares and recovery behaviors to avoid future injury. He was able to train during all season without pain and competed on Olympic Games with best physical performance.

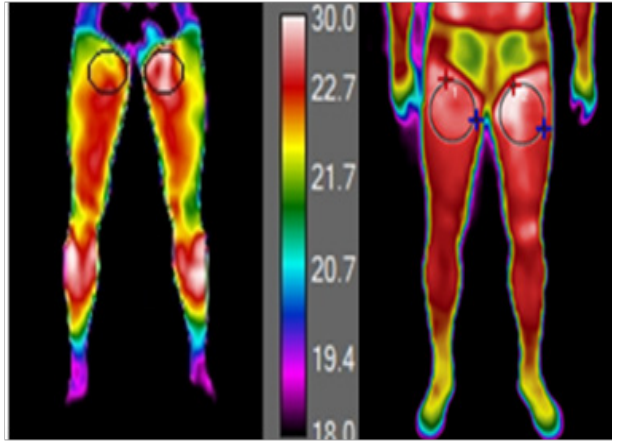

Figure 5 MIT images before and after PT intervention (region of interest were marked: medial thigh).

\section{Case 4: A 25-year-old Brazilian swimmer, whose main event is $200 \mathrm{~m}$ butterfly}

Athlete reports significant fatigue in lower limbs few hours after intense training that was characterized by 18 on perceived exertion. Figure 6 shows a hyper-radiation on lateral gastrocnemius of both legs (Figure 6). It represents an overload muscle area consistent with his complain. To avoid a future injury, some mechanisms for athlete's recovery were established, like: pneumatic compression boots, electrotherapy (modulated current for recovery) and sports massage. After two days of treatment, the average temperature of the legs was reduced by $1.1^{\circ} \mathrm{C}$ (Table 1 ). The athlete was followed throughout the season to avoid any injury and was oriented to do the same recovery mechanisms in case of intensive exercise.

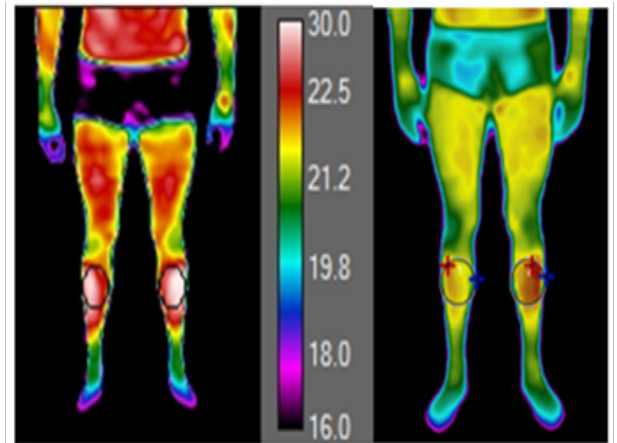

Figure 6 MIT images before and after PT intervention (region of interest were marked: lateral gastrocnemius).

\section{Conclusion}

The results demonstrated the importance of the use of thermography and the possibilities of intervention according to the data and the consequent improvement in clinical and training aspects that were also recorded in the thermographic images. In addition, the study presents data so far not demonstrated and discussed in scientific literature regarding the use of MIT in elite athletes to recovery, prevent injuries and improve performance. This study has also shown that $80 \%$ of the evaluated group had an asymmetric termogram before the intervention.

The main advantage of thermography was the security functional evaluation that brought different applications in these cases of Olympic athletic swimmers: diagnosis, injury prevention, evaluation of the sporting gesture and monitoring of training load that could be repeated anytime if necessary.

Thermography has the potential to complement evaluation and support the decisions in sports medicine in association with clinical examination and monitor the cutoff point to prevention of injuries.

\section{Acknowledgements}

None.

\section{Conflict of interest}

Authors declare that there are no conflicts of interest.

\section{References}

1. Sabato TM, Walch TJ, Caine DJ. The elite young athlete: strategies to ensure physical and emotional health. J Sports Med. 2016;7:99-113.

2. Steffens D, Maher CG, Pereira LS, et al. Prevention of Low Back Pain: A Systematic Review and Meta-analysis. JAMA Intern Med. 2016;176(2):199-208.

3. Nichols AW. Medical Care of the Aquatics Athlete. Curr Sports Med Rep. 2015;14(5):389-396.

4. Bales J, Bales K. Swimming overuse injuries associated with triathlon training. Sports Med Arthrosc. 2012;20(4):196-9.

5. Elliot RL, Head JF. Medical infrared imaging in the twenty-first century. Therm Intern. 1999;9(4):111.

6. Charkoudian N. Skin blood flow in adult human thermoregulation: how it works,when it does not and why. Mayo Clin Proc. 2003:78:603-612.

7. Ring EFJ, Ammer K. Infrared thermal imaging in medicine. Physiol Meas. 2012;33:33-46.

8. Hildebrandt C, Raschner C, Ammer K. An Overview of Recen Application of Medical Infrared Thermography in Sports Medicine in Austria. Sensors. 2010;10(5):4700-4715.

9. Merla A, Mattei PA, Di Donato L, et al. Thermal imaging of cutaneous temperature modifications in runners during graded exercise. Ann Biomed Eng. 2010;38(1):158-163.

10. Melnizky P, Schartelmüller T, Ammer K. Prüfung der intra- und interindividuellen Verlässlichkeit der Auswertung von InfrarotThermogrammen. Eur J Thermo. 1997;7:224-226.

11. Rogalski A. Recent progress in infrared detector technologies. Infrared Phys Technol. 2011;54:136-154.

12. Dibai FAV, Guirro RRJ. Evaluation of myofascial trigger points using infrared thermography: a critical review of the literature. J Manipulative and Physiol Ther. 2014:38(1):86-92.

13. Ring EFJ, Ammer K. Thermal imaging in sports medicine. Sport Med Today. 1998;1(2):108-109.

14. Hardaker NJ, Moss AD, Richards J, et al. The relationship between skin surface temperature measured via non-contact thermal imaging and intra-muscular temperature of the rectus femoris muscle. Therm Intern. 2007;17(2): 45-50.

15. Ferreira JJ, Mendonça LC. Exercise-associated thermographic changes in young and elderly subjects. Ann Biomed Eng. 2008: 36(8):14-20. 
16. 16. Selfe J, Whitaker J, Hardaker N. A narrative literature review identifying the minimum clinically important difference for skin temperature asymmetry at the knee. Therm Intern. 2008;18(2):41-44.

17. Brukner P, Khan K. Clin Sports Medicine. 2006

18. Côrte AC, Hernandez AJ. Termografia médica infravermelha aplicada à Medicina do Esporte. Rev Bras Med Esporte. 2016;22(4):315-319.

19. Stager JM, Tanner DA. Natação Manual de medicina e ciência do esporte 2nd ed. Manole; 2008.

20. Arfaoui A, Polidori G, Taiar R, et al. Infrared Thermography in Sports
Activity, Infrared Thermography. Intech. 2012:7:141-168.

21. Lavoie JM, Montpetit R. Applied physiology of swimming. Sport Med. 1986;3(3):165-189.

22. Suk MH, Yu KH, Shin YA. Comparasion of tests for measuring maximal exercise ability in elite swimmers. J Exerc Rehabil 2016;12(3):209-15.

23. Brioschi ML, Teixeira MJ, Yeng LT, et al. Manual de Termografia Médica. 1 st ed. Editora Andreoli; 2012.

24. Plassman P, Ring EFJ, Jones CD. Quality assurance of thermal imaging systems in medicine. Therm Intern. 2006:16(1):10-1. 